\title{
BMJ Open Relationship between women's smoking and laryngeal disorders based on the urine cotinine test: results of a national population-based survey
}

\author{
Haewon Byeon, ${ }^{1}$ Dongwoo Lee, ${ }^{2}$ Sunghyoun $\mathrm{Cho}^{3}$
}

To cite: Byeon H, Lee D, Cho S. Relationship between women's smoking and laryngeal disorders based on the urine cotinine test: results of a national populationbased survey. BMJ Open 2016;6:e012169.

doi:10.1136/bmjopen-2016012169

- Prepublication history for this paper is available online. To view these files please visit the journal online (http://dx.doi.org/10.1136/ bmjopen-2016-012169).

Received 6 April 2016 Revised 31 October 2016 Accepted 3 November 2016

CrossMark

\begin{abstract}
${ }^{1}$ Department of Speech Language Pathology \& Audiology, School of Public Health, Nambu University, Gwangju, Republic of Korea ${ }^{2}$ Department of Physical Therapy, School of Public Health, Honam University, Gwangju, Republic of Korea ${ }^{3}$ Department of Physical Therapy, School of Public Health, Nambu University, Gwangju, Republic of Korea
\end{abstract}

Correspondence to Professor Sunghyoun Cho; nambupt@naver.com

\section{ABSTRACT}

Objectives: There is a possibility of underestimation in the smoking rate surveyed by self-reported questionnaires. This study investigated the difference between the Korean female smoking rate as determined by self-reports and that determined by a biochemical test and elucidated the relationship between women's smoking and laryngeal disorders.

Design: Nationwide cross-sectional survey. Setting: 2008 Korea National Health and Nutrition Examination Survey.

Participants: 1849 women who completed the health survey, urinary cotinine test and laryngoscope examinations.

Main outcome measure: This study defined smokers as those with urine cotinine contents of $50 \mathrm{ng} / \mathrm{mL}$ and over. Confounding factors included age, level of education, household income, occupation and problem drinking in the past year. For statistical tests, $\mathrm{OR}$ and $95 \% \mathrm{Cl}$ were presented by using complex samples logistic regression.

Results: While there was no relationship between smoking as determined by a self-reported questionnaire and laryngeal disorders, smoking as determined by the urine cotinine test had a significant relationship with laryngeal disorders $(p<0.05)$. After all the confounding factors were adjusted, those with urine cotinine concentrations of over $50 \mathrm{ng} / \mathrm{mL}$ had a 2.1 times higher risk of laryngeal disorders than those with urine cotinine concentrations of $<50 \mathrm{ng} / \mathrm{mL}$ (OR=2.05, 95\% Cl 1.11 to 3.78$)(p<0.05)$.

Conclusions: This national cross-sectional study verified that smoking is a significant risk factor for laryngeal disorders. Longitudinal studies are required to identify the causal relationship between smoking and laryngeal disorders.

\section{INTRODUCTION}

Although the smoking rate in Korea is very high, there is a stark difference between the two genders. According to Health Data $2014,{ }^{1}$ the male smoking rate was $37.6 \%$ as of 2012, which is the highest among

\section{Strengths and limitations of this study}

- This is the first national population-based study to examine the relationship between women's smoking as determined by a biochemical test and laryngeal disorders.

- We verified the relationship between smoking and laryngeal disorders, which has not been identified in previous epidemiological studies, by using representative epidemiological data.

- In terms of limitations, there is a possibility that environmental factors, such as secondhand smoking, affected cotinine concentrations on the urine cotinine test, and there is also a possibility that occasional smokers were not classified as smokers due to their low cotinine concentrations.

Organization for Economic Cooperation and Development (OECD) countries, whereas the female smoking rate was only $5.8 \%$, the lowest among OECD countries. The female smoking rate of Korea is just one-quarter of that of France $(20.2 \%)$ and the Czech Republic (19.6\%) and only one-third of the average female smoking rate of OECD countries $(16.0 \%) .{ }^{1}$ In addition, since the female smoking rate has remained as low as $5-6 \%$ over the past decade, ${ }^{2}$ women have drawn less attention than men in terms of no-smoking policies.

Recent epidemiological studies have indicated the possibility that women's smoking in Korea as determined by self-reports might be underestimated. ${ }^{3}{ }^{4}$ Park et al measured the female smoking rate with urine cotinine concentrations and found that the female smoking rate in Korea was $18.2 \%$, triple the self-reported smoking rate. In particular, women in their 30s had a biochemical test smoking rate that was three times higher than their self-reported smoking rate. ${ }^{3}$ The female smoking rate in Korea, as determined by urine cotinine concentration, is higher 
than the average female smoking rate of OECD countries. Since smoking rates differ considerably depending on the survey methods used, epidemiological studies need to be conducted based on precise smoking surveys in order to establish health-promotion plans based on solid grounds.

Meanwhile, smoking is known to be a risky behaviour for laryngeal health. Cigarette smoke contains 7357 kinds of chemical substances, including nitrosamines and radioactive compounds, and among them, benzopyrene, arsenic and cadmium are typical carcinogens that are significantly related to the onset of laryngeal cancer. ${ }^{5}$ In an animal experiment, smoking was verified to cause anatomical changes of the larynx by drying up the mucous membrane of the vocal cords. ${ }^{6}$ In addition, numerous epidemiological studies and case-controlled studies have reported that excessive smoking is a major risk factor for benign laryngeal lesions of the vocal nodules, ${ }^{7}$ as well as for Reinke's oedema and laryngeal leucoplakia as well. ${ }^{8} 9$

Smoking is a cause of laryngeal disorders that incurs enormous social costs due to increased medical costs, as well as loss of labour from hospitalisation and absence from work. Approximately $44-57 \%$ of teachers experience laryngeal disorders, such as vocal nodules ${ }^{10}{ }^{11}$ and in the case of the USA, the social cost from communication disorders amounts to $2.5 \%$ of gross national product. $^{12}$ In Korea, social and economic losses for smokers are estimated to be a total of $\mathrm{U} \$ 2.8$ billion, $0.3 \%$ of gross domestic product, as of 2007 , and among them, losses from laryngeal cancer alone are estimated to be over $\mathrm{U} \$ 42000000{ }^{13}$ Therefore, in order to reduce laryngeal disorders from smoking and the resultant social costs, it is necessary to establish an effective no-smoking policy to address this preventable risk factor.

Unlike comparison studies on patient groups and reports on animal experiments that consistently indicate that smoking adversely affects the larynx, the relationship between smoking and laryngeal disorders in epidemiological studies on community-dwelling populations is controversial. While smoking had a significant relationship with laryngeal disorders in an epidemiological study on Korean adults, ${ }^{14}$ there was no significant relationship between smoking and dysphonia in the study by Roy et $a l^{15}$ on the general US population. There is a possibility that this difference in the results of the studies may be due to the differences in study methods rather than meaning that there is no relationship between smoking and laryngeal disorders. Most preceding studies on the relationship between smoking and dysphonia investigated whether participants smoked or not based on self-reported surveys. ${ }^{15-17}$

Health risk behaviour such as smoking is likely to be underestimated when surveyed with self-reported questionnaires. Since East Asian countries have especially strong negative perceptions of women smokers, they tend not to let other people around them know about their smoking. ${ }^{2} 41819$ According to Park et $a l,^{3}$ a higher proportion of females hid their smoking than males, and one out of every two female smokers hid their smoking behaviour in self-reported questionnaire surveys. Since the self-reported smoking rate is likely to be underestimated, biochemical tests are required in addition to self-reported questionnaires in order to determine the exact relationship between smoking and laryngeal disorders.

In terms of biochemical tests for smoking, there are carbon monoxide concentration tests, nicotine tests and cotinine tests. Whereas nicotine has a short half-life of $30 \mathrm{~min}$ in the blood, cotinine, a substance created by the metabolism in the human body, is effective in distinguishing smoking due to its long half-life of 18-20 hours. ${ }^{20}$ In addition, cotinine is widely used as an effective index in distinguishing whether or not a participant smokes, since nicotine is influenced by the potential of hydrogen $(\mathrm{pH})$ value when excreted from the kidney in the urine, while cotinine is barely influenced by $\mathrm{pH}$ and is reported to have a sensitivity to smoking of as high as $92.6 \% .^{21}$ Nevertheless, few epidemiological studies have investigated the relationship between smoking and laryngeal disorders by using biochemical tests, and they have been limited to patient-comparison group studies. ${ }^{22}$ Moreover, until now, there has been no epidemiological study on the relationship between urine cotinine concentration and laryngeal disorders for community-dwelling populations.

This study identified the difference between the smoking rate as determined by self-reports and that determined by biochemical tests for women in local communities and investigated the relationship between women's smoking and laryngeal disorders by using a nationwide representative survey of the Korean population.

\section{MATERIALS AND METHODS}

\section{Study design}

This was a nationwide cross-sectional survey.

\section{Study population}

The participants of this study were adults, 19 years and older, who participated in the Korea National Health and Nutrition Examination Survey (KNHANES) 2008, which was a nationwide representative survey of the non-institutionalised population in the Republic of Korea, and who then participated in a health interview, urinary cotinine test and laryngoscope examination. ${ }^{23}$ The survey was approved by the Institutional Review Board (number 2010-02CON-21-C) of the Korean Center for Disease Control and Prevention (K-CDC). The KNHANES is a nationwide cross-sectional survey conducted annually by the K-CDC using a rolling sampling design that involves a complex, stratified multistage probability cluster survey of a representative sample of non-institutionalised civilians in the Republic of Korea. The sampling methods of the KNHANES are described 
in detail elsewhere. ${ }^{23}$ Briefly, the KNHANES 2008 was conducted on 12528 people from 4600 households, and the participation rate was $80.8 \% \quad(n=9744)$. This study targeted 3339 people who completed the health survey, urinary cotinine test and laryngoscope examinations. Among them, 1455 men, 32 people whose laryngoscopic findings could not be determined and 3 non-respondents to the survey on smoking were excluded from the research, and 1849 women were analysed (figure 1).

\section{Health interview and laryngoscope examination}

Trained medical staff members performed the laryngoscope examination and health interview at a mobile examination centre and at participants' households, respectively.

For the health interview, the survey on level of education and economic activity was conducted by face-to-face interviews, and the survey on behaviours regarding health (eg, smoking, alcohol consumption) was executed with self-administered questionnaires.

According to the definition of the $\mathrm{WHO},{ }^{24}$ a current smoker was defined as someone who has smoked more than 100 cigarettes over their lifetime and either sometimes smokes or smokes every day. A past smoker was defined as someone who has smoked more than 100 cigarettes during their lifetime and does not currently smoke.

Endoscopic laryngeal examinations for laryngeal pathologies were performed by an otolaryngologist with a $70^{\circ}$ endoscope on female adults. The laryngeal examinations were performed in collaboration with the Korean Society of Otorhinolaryngology-Head and Neck Surgery, which provided technical advice and highly trained otolaryngologists.

Based on data from the laryngoscopic examinations, the definition of laryngeal pathologies included vocal nodules, vocal polyps, intracordal cysts, Reinke's

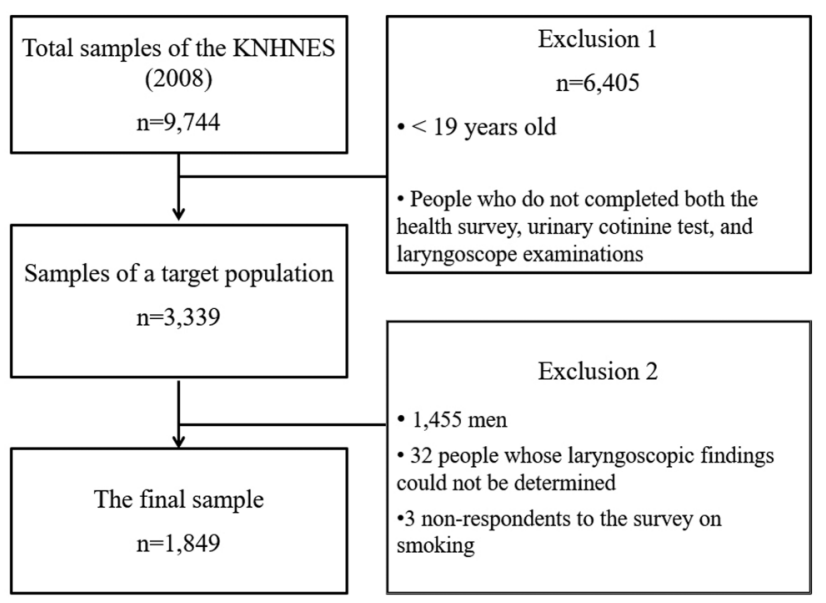

Figure 1 Flow chart for selection of study participants. KNHANES, Korea National Health and Nutrition Examination Survey. oedema, laryngeal granuloma, sulcus vocalis, laryngeal keratosis, laryngitis, laryngeal papilloma and suspected malignant neoplasm of the larynx.

\section{Urine cotinine test}

Urine samples $(5-20 \mathrm{~mL})$ were collected in trace element ethylenediaminetetraacetic acid containers. Cotinine concentration levels were measured by a mass selective detector (GC-MSD, Clarus 600 T; PerkinElmer, Waltham, Massachusetts, USA) and Urine Metals Control (Clinchek and G-EQUAS; Recipe Chemicals, Munich, Germany) was used for the comparison group. $^{23}$ Cotinine concentrations were marked in $\mathrm{ng} / \mathrm{mL}$.

Since the definitions of smoking based on the concentration of cotinine in the urine vary from study to study from 30 to $200 \mathrm{ng} / \mathrm{mL}^{25} 26$ and the metabolic rate of cotinine differs from ethnic group to ethnic group, ${ }^{27}$ this study defined smokers as those with urine cotinine contents of $50 \mathrm{ng} / \mathrm{mL}$ and over by referring to preceding studies on urine cotinine tests for Koreans. ${ }^{11} 2829$

\section{Covariates}

Age, education level, monthly mean household income, occupation and problem drinking were examined. Age was classified as 19-29, 30-39, 40-49, 50-59 years and more than 60 years. Education levels were classified as below elementary school graduation, middle school graduation, high school graduation and above college graduation. Monthly mean household income was evaluated using the open-ended question from the National Health and Nutrition Examination Survey ("What is your estimated monthly mean household income including all income sources, such as salary, real estate profit, pension, interest and government subsidies?"). It was provided as a quartile value. We defined household income by using the quartile variable of the mean monthly income estimated from the raw data. Occupations were reclassified into economically inactive (unemployed person, homemaker), non-manual (managers and professionals, clerical support workers, service and sales workers) and manual (skilled agricultural and forestry and fishery workers, craft and plant and machine operators and assemblers, and unskilled labourers) occupations. As for alcohol consumption, eight points and over was classified as problem drinking by using the Alcohol Use Disorders Identification Test in Korea (AUDIT-K). ${ }^{30}$ Coffee consumption was classified into 'one cup or less a day' and 'more than two cups a day'.

\section{Statistical analyses}

The weighted values of the KNHANES were calculated so that the participants of the survey could represent the overall Korean population. Detailed explanations on the weighted values are shown in the KNHANES. ${ }^{23}$ General characteristics, smoking rate and prevalence rate of laryngeal disorders were each presented in weighted percentages. The differences in the general characteristics between groups based on laryngeal disorders were 
verified by the Rao-Scott $\chi^{2}$ test. OR and $95 \%$ CI were presented for the relationship between subjective voice problems and dysphonia by using complex samples logistic regression. In the first stage of the study model, sociodemographic variables (age, education, monthly mean household income, occupation) were adjusted as confounding factors and in the second stage all confounding variables were adjusted. IBM SPSS V.23.0 (IBM, Chicago, Illinois, USA) was used for analyses, and the significance level was 0.05 in the two-tailed test.

\section{RESULTS}

\section{Sample characteristics}

We compared sociodemographic characteristics between overall participants and participants of analysis to confirm whether there was a selection bias, since the number of participants of analysis in our study (those who completed both the urine cotinine test and laryngendoscopy test, $\mathrm{n}=1849$ ) was smaller than the number of overall participants of the KNHANES $(n=9744)$. The results indicated that there were no significant differences in age, occupation or level of monthly mean household income.

The characteristics of the participants are presented in table 1. High school graduates $(38.2 \%)$, economically inactive individuals $(53.0 \%)$, those who experienced no problem drinking in the past year $(82.8 \%)$ and those who drank less than one cup of coffee a day $(70.8 \%)$ were high in proportion. As for smoking, on the basis of the questionnaire, $86.8 \%$ were non-smokers and $6.9 \%$ were current smokers while, on the basis of the urine cotinine test, $85.6 \%$ were non-smokers and $14.4 \%$ were current smokers. The prevalence rate of laryngeal disorders was $4.3 \%$.

\section{Female smoking rate}

The female smoking rate was the highest in the 19-29 years age group for both the self-reported questionnaire and urine cotinine test and the lowest in the $50-59$ years age group (table 2). However, the statistics on the smoking rate differed depending on the survey method. In all age groups, smoking rates based on the urine cotinine test were higher than those based on self-reported questionnaires, from a minimum of 1.6 times higher to a maximum of 3.2 times higher.

\section{Characteristics of participants based on laryngeal disorders}

According to the result of the Rao-Scott $\chi^{2}$ test (table 3 ), laryngeal disorders differed significantly with level of education $(p<0.05)$. Primary school graduates and lower had a higher prevalence rate of laryngeal disorders.

\section{Association between women's smoking and laryngeal disease}

According to the result of the complex samples logistic regression (table 4), smoking rate based on self-reported

\begin{tabular}{lc}
\multicolumn{3}{l}{ Table 1 Sample characteristics $(\mathrm{n}=1849)$} \\
\hline Characteristics & $\mathbf{n}$ (weighted \%) \\
\hline Age (years) & \\
19-29 & $239(19.5)$ \\
$30-39$ & $339(19.2)$ \\
$40-49$ & $337(20.9)$ \\
$50-59$ & $334(18.3)$ \\
$60+$ & $600(22.2)$ \\
Education level & \\
Below elementary school graduation & $714(29.2)$ \\
Middle school graduation & $192(10.5)$ \\
High school graduation & $588(38.2)$ \\
Above college graduation & $354(22.1)$ \\
Monthly mean household income & \\
1st quartile & $423(17.7)$ \\
2nd quartile & $479(28.6)$ \\
3rd quartile & $478(28.5)$ \\
4th quartile & $424(25.2)$ \\
Occupation & \\
Economically inactive population & $958(53.0)$ \\
Non-manual worker & $441(27.3)$ \\
Manual worker & $446(19.7)$ \\
Problem drinking & \\
No & $1600(82.8)$ \\
Yes & $249(17.2)$ \\
Coffee consumption & \\
One cup and less a day & $1193(70.8)$ \\
More than 2 cups a day & $487(29.2)$ \\
Self-reported questionnaires & $1636(86.8)$ \\
Non-smoker & $107(6.3)$ \\
Past smoker & $106(6.9)$ \\
Current smoker & $1609(85.6)$ \\
Urine cotinine test & $240(14.4)$ \\
Non-smoker $(<50$ mL) & \\
Current Smoker ( $\geq 50$ mL) & $1757(95.7)$ \\
Laryngeal disorders & $92(4.3)$ \\
No & \\
Yes & \\
\hline & \\
& \\
\hline &
\end{tabular}

\begin{tabular}{llll} 
Table 2 & Women's smoking rate based on age (weighted \%) \\
\hline $\begin{array}{l}\text { Age } \\
\text { (years) }\end{array}$ & $\begin{array}{l}\text { Self-reported } \\
\text { questionnaires }\end{array}$ & $\begin{array}{l}\text { Urine } \\
\text { cotinine test }\end{array}$ & $\begin{array}{l}\text { Difference in } \\
\text { smoking rate }\end{array}$ \\
\hline $19-29$ & 14.4 & 22.5 & 8.1 \\
$30-39$ & 6.6 & 15.0 & 8.4 \\
$40-49$ & 4.7 & 14.9 & 10.2 \\
$50-59$ & 3.0 & 8.3 & 5.3 \\
$60+$ & 6.1 & 11.3 & 5.2 \\
\hline
\end{tabular}

questionnaires did not have a relationship with laryngeal disorders, while smoking rate based on the urine cotinine test had a significant relationship with laryngeal disorders $(p<0.05)$. When all confounding factors were adjusted in model 2, those with urine cotinine concentrations of $50 \mathrm{ng} / \mathrm{mL}$ and over had a 2.1 times $(\mathrm{OR}=2.05,95 \%$ CI 1.11 to 3.78$)$ higher risk of laryngeal disorders than those with urine cotinine concentrations of $<50 \mathrm{ng} / \mathrm{mL}(\mathrm{p}<0.05)$. 
Table 3 Characteristics of participants based on laryngeal disorders, n (weighted \%)

\begin{tabular}{|c|c|c|c|}
\hline \multirow[b]{2}{*}{ Variables } & \multicolumn{2}{|c|}{$\begin{array}{l}\text { Laryngeal } \\
\text { disorders }(n=1849)\end{array}$} & \multirow[b]{2}{*}{ p Value } \\
\hline & $\begin{array}{l}\text { No } \\
(n=1752)\end{array}$ & $\begin{array}{l}\text { Yes } \\
(n=92)\end{array}$ & \\
\hline Age (years) & & & 0.157 \\
\hline $19-29$ & $230(96.6)$ & $9(3.4)$ & \\
\hline 30-39 & 328 (97.2) & $11(2.8)$ & \\
\hline $40-49$ & $323(96.5)$ & $14(3.5)$ & \\
\hline $50-59$ & $312(94.2)$ & $22(5.8)$ & \\
\hline $60+$ & $564(94.1)$ & $36(5.9)$ & \\
\hline Education level & & & 0.015 \\
\hline $\begin{array}{l}\text { Below elementary school } \\
\text { graduation }\end{array}$ & $666(93.4)$ & $48(6.6)$ & \\
\hline Middle school graduation & $188(98.4)$ & $4(1.6)$ & \\
\hline High school graduation & $565(96.5)$ & $23(3.5)$ & \\
\hline Above college graduation & $337(96.0)$ & $17(4.0)$ & \\
\hline $\begin{array}{l}\text { Monthly mean household } \\
\text { income }\end{array}$ & & & 0.84 \\
\hline 1st quartile & $392(92.4)$ & $31(7.6)$ & \\
\hline 2nd quartile & $460(96.4)$ & $19(3.6)$ & \\
\hline 3rd quartile & $456(95.8)$ & $22(4.2)$ & \\
\hline 4th quartile & $405(96.6)$ & $19(3.4)$ & \\
\hline Occupation & & & 0.755 \\
\hline $\begin{array}{l}\text { Economically inactive } \\
\text { population }\end{array}$ & $906(95.6)$ & $52(4.4)$ & \\
\hline Non-manual worker & 419 (95.2) & $22(4.8)$ & \\
\hline Manual worker & $428(96.6)$ & $18(3.4)$ & \\
\hline Problem drinking & & & 0.727 \\
\hline No & 1519 (95.6) & $81(4.4)$ & \\
\hline Yes & $238(96.1)$ & $11(3.9)$ & \\
\hline Coffee consumption & & & 0.125 \\
\hline One cup and less a day & $1130(95.5)$ & $63(4.5)$ & \\
\hline More than 2 cups a day & $471(97.1)$ & $16(2.9)$ & \\
\hline $\begin{array}{l}\text { Self-reported } \\
\text { questionnaires }\end{array}$ & & & 0.709 \\
\hline Non-smoker & $1558(95.8)$ & $78(4.2)$ & \\
\hline Past smoker & $99(94.1)$ & $8(5.9)$ & \\
\hline Current smoker & $100(96.0)$ & $6(4.0)$ & \\
\hline Urine cotinine test & & & 0.509 \\
\hline Non-smoker (<50 mL) & $1533(95.8)$ & $76(4.2)$ & \\
\hline Current Smoker ( $\geq 50 \mathrm{~mL})$ & $224(94.0)$ & $16(6.0)$ & \\
\hline
\end{tabular}

\section{DISCUSSION}

Since there is a difference between the female smoking rate based on self-reported questionnaires and the actual smoking rate, there is a possibility of a difference in the relationship between smoking and laryngeal disorders depending on the survey method used. This study identified the difference between the smoking rate as determined by self-reports and that determined by biochemical tests for women over the age of 19 years in local communities by using the 2008 KNHANES and investigated the relationship between women's smoking and laryngeal disorders.

In this study, there was a difference between the female smoking rate based on the questionnaire survey and that based on the urine cotinine test. Although the Canadian Health Measures Survey reported that there was no significant difference between the female smoking rate based on a self-reported survey and that based on a urine cotinine test, ${ }^{31}$ numerous epidemiological studies have consistently reported, as in this study, that the female smoking rate based on questionnaire surveys is less than that based on biophysical tests. $^{32} 33$ In addition, a systematic review on the relationship between the accuracy of the self-reported smoking rate and that of biophysical tests also indicated that the self-reported smoking rate tends to be underestimated. ${ }^{34}$

This trend of false response in self-reported questionnaires has been reported to be higher in women than men in Korea. According to Jung-Choi's study, which investigated gender differences in the smoking rate determined by self-reports and that determined by urine cotinine tests, six times as many females than males hid their smoking behaviour. ${ }^{4}$ In addition, in Lee and Seo's study, although the male smoking rate differed little based on different survey methods, $13 \%$ of women responded that they smoked in an anonymous questionnaire survey, while $21.4 \%$ of women responded that they smoked in a survey conducted using the bogus pipeline technique, displaying a significant double difference. ${ }^{18}$ Another study comparing the female smoking rates of the self-reported smoking status and the cotinine test also pointed out that we could underestimate the female smoking rate if we rely on the smoking rate of the selfreported smoking status. ${ }^{35}$ These results imply that a large number of women smokers are likely to hide their smoking habit in questionnaire surveys. In particular, according to the results of the investigation on women's smoking based on age in this study, the smoking rate in women in their 20 s was the highest in the cotinine test, as in the questionnaire survey and there were bigger differences in smoking rates depending on the survey method in women under 40 years than in women over 50. Korea Centers for Disease Control and Prevention reported that the difference in smoking rate among investigation methods was larger for relatively younger women. ${ }^{36}$ Both the self-reported smoking status and the cotinine test showed that smoking rate was the highest in the 20-49 years old female group. ${ }^{36}$ However, the smoking rate calculated from the cotinine test was two times higher than that from the self-reported smoking status. ${ }^{36}$ Moreover, a study evaluating the smoking of pregnant women (18-38 years) also showed that the smoking rate from the self-reported smoking status was $4.1 \%$ while that from the cotinine test was $10.7 \% .^{37}$ In a questionnaire survey on smoking women in Korea, $29.2 \%$ of women smokers in their $20 \mathrm{~s}$ and $30 \mathrm{~s}$ responded that they smoked only when they were alone, and $25 \%$ responded that their families knew about their smoking. Only $2.2 \%$ of smoking women smoke in public smoking places in their workplaces and campuses. This result supports the possibility that there may be many young women in Korea who hide their smoking. ${ }^{19}$ 
Table 4 Complex samples logistic regression analyses of the association between women's smoking (self-reported smoking status and cotinine level) and laryngeal disease, OR (95\% Cl)

\begin{tabular}{|c|c|c|c|}
\hline & Crude model & Model 1 & Model 2 \\
\hline \multicolumn{4}{|l|}{ Self-reported questionnaires } \\
\hline Past smoker & $1.61(0.76$ to 3.43$)$ & $1.64(0.76$ to 3.58$)$ & $1.75(0.75$ to 4.06$)$ \\
\hline Current smoker & 1.19 (0.51 to 2.82$)$ & 1.43 (0.59 to 3.44$)$ & 1.56 (0.58 to 4.13$)$ \\
\hline \multicolumn{4}{|l|}{ Urine cotinine test } \\
\hline Current Smoker ( $\geq 50 \mathrm{~mL})$ & $1.44(0.82$ to 2.52$)$ & 1.68 (0.96 to 2.99$)$ & $2.05(1.11 \text { to } 3.78)^{\star}$ \\
\hline
\end{tabular}

There are two possible explanations for the greater difference in the smoking rates of women of childbearing age depending on the survey method than those of the other age groups. First, there is a prejudice that smoking women tend to be sexually more promiscuous. There is a perception that smoking women are more promiscuous than smoking men, ${ }^{38}$ and this negative image is particularly striking in young women smokers in Korea. ${ }^{39}$ Second, it could be due to the logic that female smoking is much more dangerous than male smoking, as women of childbearing age may give birth. Even though smoking has adverse effects on both men and women, women's smoking is perceived as more dangerous, because it can harm the fetus's health. ${ }^{39}$ In the study of Jhun $e t a l^{32}$ on pregnant women selected by random sampling, the self-reported smoking rate was $0.55 \%$, while the smoking rate as determined by the urine cotinine test $(>100 \mathrm{ng} / \mathrm{mL})$ was surprisingly six times higher, $3.03 \%$ and the degree of agreement between the two tests (Cohen's $\kappa$ Coefficient) was as low as 0.2.

Even though the smoking rates acquired from selfreported questionnaire surveys are untrustworthy due to the high possibility that women smokers will hide their smoking behaviour in open questionnaire surveys, many epidemiological studies have measured smoking rates by using self-reported questionnaires. ${ }^{15}{ }^{16}$ It is necessary to additionally conduct biochemical tests, such as the urine cotinine test, to confirm the exact smoking rate in future studies on women smokers and to establish a no-smoking policy, because there is a high possibility of underestimation when adopting the smoking rate only based on self-reported questionnaire surveys.

In this study, based on the self-report questionnaire, neither past smoking nor current smoking had a significant relationship with laryngeal disorders, whereas, on the basis of the cotinine test, smoking women had a 2.1 times greater chance of suffering from laryngeal disorders than non-smoking women. Smoking is known to hamper the effective vibration of the vocal cords by directly affecting the mucous membrane of the vocal cords. In their study on smokers' voices, Gonzalaz and Carpi ${ }^{40}$ reported that nicotine has a neurological influence on the larynx, causing unstable vibration of the vocal cords, which lowers the quality of the voice. In addition, smoking is known to be a major risk factor for laryngeal disorders. When a person smokes excessively over a long period of time, harmful substances, such as nicotine and tar, directly stimulate the mucous membrane of the vocal cords while passing through the oral cavity and the larynx, causing inflammatory changes and raising the risk of laryngeal disorders, such as leucoplakia and laryngeal cancer. $^{7-9}$ According to the 2014 Korea National Cancer Incidence Database, the laryngeal cancer rate from smoking has reached an astounding $70.3 \%{ }^{41}$ In addition, the Korean Cancer Prevention Study, which traced 1178138 Korean adults for 11 years, also reported that women smokers have a 4.2 times higher risk of death from laryngeal cancer than non-smokers. $^{42}$

Although smoking has been verified to be a clear pathogenic factor for laryngeal disorders, such as laryngeal cancer, in an epidemiological study on adults in local communities by Roy et al, ${ }^{15}$ duration of smoking, age at which participants started smoking, and smoking amount based on a self-report questionnaire had no significant relationship with dysphonia. Similarly, this study did not show a significant relationship between selfreported smoking and laryngeal disorders. There are two possible explanations. First, we did not have enough patients with laryngeal disorders. Second, some smokers indicated that they were non-smokers on the self-report questionnaire and these false responses influenced the relationship between self-reported smoking and laryngeal disorders. In this study, the estimated smoking rate from the urine cotinine test was more than twice that reported in the self-report questionnaire. This implies that by only using statistics from self-report questionnaires, it is difficult to investigate the exact proportion of women smokers and also limits our ability to determine the precise relationship between smoking and laryngeal disorders.

South Korea enacted the National Health Promotion Law in 1995 and established a nationwide antismoking policy. It later enacted Health Plan $2020^{43}$ in 2011 to reduce the smoking rate from $40 \%$ to $29 \%$ by 2020 by employing antismoking policies, such as tobacco advertisement regulations, establishment of non-smoking areas, tobacco price increases and antismoking education. Nevertheless, there are insufficient antismoking policies reflecting the characteristics of females at the 
national level. ${ }^{44}$ This is because the self-report questionnaire conducted by the Ministry of Health and Welfare showed that the female smoking rate in South Korea was $5-6 \%$ in the past 10 years, which is much lower than that in other OECD countries. ${ }^{36}$ Until now, the issue of female smoking has drawn less attention than that of male smoking. However, this study showed that it was difficult to accurately identify the female smoking rate by only using the self-report questionnaire and it was impossible to find relationships with other diseases. Biochemical tests (eg, cotinine test) are needed in addition to the self-report questionnaire to accurately identify the relationship between smoking and laryngeal disorders and establish effective female antismoking programmes based on the information. Furthermore, the development and dissemination of a manual and an antismoking programme designed specifically for female smokers and reflecting the characteristics of female smokers in order to prevent laryngeal disorders in women is urgently needed.

This study's strength lies in the fact that it verified the relationship between smoking and laryngeal disorders, which has not been identified in previous epidemiological studies, by using representative epidemiological data. However, there are some limitations to our study. First, women who last smoked more than 3 days ago may not have been classified as smokers in the urine cotinine test. Since urine cotinine has a short half-life of 1618 hours, it shows a positive reaction only when the last incidence of smoking occurred within the past 2-3 days. Thus, there is a possibility that occasional smokers who did not smoke daily might not have been reflected in the study result. Second, environmental factors, such as secondhand smoking, might have affected urine cotinine concentrations. Since those with cotinine concentrations of $50 \mathrm{ng} / \mathrm{mL}$ and over cannot necessarily be defined as smokers, caution should be taken in interpreting the study results. Third, there may be potential confounding factors related to laryngeal disease other than those included in this study. In particular, laryngopharyngeal reflux or gastro-oesophageal reflux disease and medical history on laryngeal disorders were not investigated. Fourth, this study could not use the latest data because the urine cotinine test was performed until 2008. It will be necessary to identify the relationship between passive smoking and laryngopathy by using the latest urine cotinine data for a larger sample size. Fifth, since this is a cross-sectional study, relationships between variables are not to be interpreted as being causal.

\section{CONCLUSION}

In this epidemiological study, smoking was verified to be a significant risk factor for laryngeal disorders. In order to prevent laryngeal disorders in the future, it is necessary to establish a detailed no-smoking policy that includes hidden women smokers as well. Furthermore, longitudinal studies are required to verify the causal relationship between smoking and laryngeal disorders.
Acknowledgements The authors would like to acknowledge the Korea Centers for Disease Control and Prevention that provided the raw data for analysis.

Contributors $\mathrm{HB}$ conceived and designed the experiments. HB and SC analysed the low data. $\mathrm{HB}, \mathrm{SC}$ and $\mathrm{DL}$ wrote the paper. All authors were actively and substantially involved in drafting the article and final approval of the version to be published.

Funding This research received no specific grant from any funding agency in the public, commercial or not-for-profit sectors.

Competing interests None declared.

Patient consent Obtained.

Provenance and peer review Not commissioned; externally peer reviewed.

Data sharing statement No additional data are available.

Open Access This is an Open Access article distributed in accordance with the Creative Commons Attribution Non Commercial (CC BY-NC 4.0) license, which permits others to distribute, remix, adapt, build upon this work noncommercially, and license their derivative works on different terms, provided the original work is properly cited and the use is non-commercial. See: http:// creativecommons.org/licenses/by-nc/4.0/

\section{REFERENCES}

1. OECD Health Statistics, OECD Health data. 2014. http://www.oecd org/els/health-systems/oecd-health-statistics-2014-frequentlyrequested-data.htm (accessed 20 Mar 2016).

2. Seo MK. Women's smoking behavior: factors and policy options. Health Welfare Policy Forum 2011:172:59-67.

3. Park MB, Kim CB, Nam EW, et al. Does South Korea have hidden female smokers: discrepancies in smoking rates between self-reports and urinary cotinine level. BMC Womens Health 2014; 14:156.

4. Jung-Choi $\mathrm{KH}$, Khang $\mathrm{YH}$, Cho HJ. Hidden female smokers in Asia: a comparison of self-reported with cotinine-verified smoking prevalence rates in representative national data from an Asian population. Tob Control 2012;21:536-42.

5. Rodgman A, Perfetti TA, The chemical components of tobacco and tobacco smoke. Boca Raton: CRC Press, Taylor \& Francis Group, 2009.

6. Duarte JL, de Faria FA, Ceolin DS, et al. Effects of passive smoke inhalation on the vocal cords of rats. Braz J Otorhinolaryngol 2006;72:210-16.

7. Byeon $\mathrm{H}$. Relationships among smoking, organic, and functional voice disorders in Korean general population. $J$ Voice 2015;29:312-16.

8. Schultz P. Vocal fold cancer. Eur Ann Otorhinolaryngol Head Neck Dis 2011:128:301-8.

9. Marcotullio D, Magliulo G, Pezone T. Reinke's edema and risk factors: clinical and histopathologic aspects. Am J Otolaryngol 2002;23:81-4.

10. The Korean Federation of Teacher's Associations. Teachers awareness survey. Seoul: The Korean Federation of Teacher's Associations, 2011.

11. Roy N, Merrill RM, Thibeault S, et al. Prevalence of voice disorders in teachers and the general population. J Speech Lang Hear Res 2004;47:281-93.

12. Ruben RJ. Redefining the survival of the fittest: communication disorders in the 21st century. Laryngoscope 2000;110:241-5.

13. Park SE, Song HR, Kim CH, et al. Economic burden of smoking in Korea 2007. Korean J Health Promot Dis Prev 2008;8:219-27.

14. Byeon $\mathrm{H}$. The risk factors of laryngeal pathology in Korean adults using a decision tree model. $J$ Voice 2015;29:59-64.

15. Roy N, Merrill RM, Gray SD, et al. Voice disorders in the general population: prevalence, risk factors, and occupational impact. Laryngoscope 2005;115:1988-95.

16. Sorensen D, Horii Y. Cigarette smoking and voice fundamental frequency. $J$ Commun Dis 1982;15:135-44.

17. Awan SN. The effect of smoking on the dysphonia severity index in females. Folia Phoniatr Logop 2011;63:65-71.

18. Lee S, Suh K. Moderate effects of gender on the knowledge and attitude toward smoking and self-concept among high school students. Korean J Health Edu Promot 2006:23:29-45.

19. Korea Institute for Health and Social Affairs. Women's use of tobacco and alcohol and countermeasures. Seoul: Korea Institute for Health and Social Affairs, 2008. 
20. Scott DA, Palmer RM, Stapleton JA. Validation of smoking status in clinical research into inflammatory periodontal disease. J Clin Periodontol 2001;28:715-22.

21. Park SS, Lee JY, Cho SI. [Validity of expired carbon monoxide and urine cotinine using dipstick method to assess smoking status] $J$ Prev Med Public Health 2007;40:297-304.

22. Lubin $\mathrm{JH}$, Purdue M, Kelsey $\mathrm{K}$, et al. Total exposure and exposure rate effects for alcohol and smoking and risk of head and neck cancer: a pooled analysis of case-control studies. Am J Epidemiol 2009;170:937-47.

23. Ministry of Health and Welfare. Korea National Health and Nutrition Examination Survey (KNHANES) 2008. Seoul: Ministry of Health and Welfare, 2010.

24. World Health Organization. Guidelines for controlling and monitoring the tobacco epidemic. Geneva: World Health Organization, 1988.

25. Caraballo RS, Giovino GA, Pechacek TF. Self-reported cigarette smoking vs. serum cotinine among US adolescents. Nicotine Tob Res 2004;6:19-25.

26. Haufroid V, Lison D. Urinary cotinine as a tobacco-smoke exposure index: a minireview. Int Arch Occup Environ Health 1998;71:162-8.

27. Nakajima M, Fukami T, Yamanaka $\mathrm{H}$, et al. Comprehensive evaluation of variability in nicotine metabolism and CYP2A6 polymorphic alleles in four ethnic populations. Clin Pharmacol Ther 2006;80:282-97.

28. Park SW, Kim JY. Validity of self-reported smoking using urinary cotinine among vocational high school students. J Prev Med Public Health 2009;42:223-30.

29. Kang HG, Kwon KH, Lee IW, et al. Biochemically-verified smoking rate trends and factors associated with inaccurate self-reporting of smoking habits in Korean women. Asian Pac J Cancer Prev 2013;14:6807-12.

30. Oh MK, Kim JS, Park BK, et al. Screening criteria of alcoholism by alcohol use disorders identification test (AUDIT) in Korea. J Korean Acad Fam Med 1999;20:1152-9.

31. Wong SL, Shields M, Leatherdale S, et al. Assessment of validity of self-reported smoking status. Health Rep 2012;23:47-53.

32. Jhun HJ, Seo HG, Lee DH, et al. Self-reported smoking and urinary cotinine levels among pregnant women in Korea and factors associated with smoking during pregnancy. J Korean Med Sci 2010;25:752-7.

33. Tyrpień K, Bodzek P, Mańka G. Application of planar chromatography to the determination of cotinine in urine of active and passive smoking pregnant women. Biomed Chromatogr 2001;15:50-5.

34. Connor Gorber S, Schofield-Hurwitz S, Hardt J, et al. The accuracy of self-reported smoking: a systematic review of the relationship between self-reported and cotinine-assessed smoking status. Nicotine Tob Res 2009;11:12-24.

35. Dietz PM, Homa D, England LJ, et al. Estimates of nondisclosure of cigarette smoking among pregnant and nonpregnant women of reproductive age in the United States. Am J Epidemiol 2011;173:355-9.

36. Korea Centers for Disease Control and Prevention, Korea Health Statistics 2013: Korea National Health and Nutrition Examination Survey. Osong: Korea Centers for Disease Control and Prevention, 2014.

37. Hawkins SS, Dacey C, Gennaro S, et al. Secondhand smoke exposure among nonsmoking Pregnant Women in New York City. Nicotine Tob Res 2014;16:1079-84.

38. Hall SM. Women and drugs. In: Adesso VJ, Reddy DM, Fleming R eds. Psychological perspectives on women's health. Washington DC: Taylor \& Francis, 1994:101-26.

39. Nam IS. Discrimination based on gender in Korean society: discourses on the negative image of female smokers in Korea. Korean J Soc Theory 2003;23:131-73.

40. Gonzalaz J, Carpi A. Early effects of smoking on the voice: a multidimensional study. Med Sci Monit 2004;10:CR649-56.

41. Ministry of Health and Welfare. Korea National cancer Incidence Database 2014. Osong: Ministry of Health and Welfare, 2015.

42. Jee SH, Yun JE, Park JY, et al. Smoking and cause of death in Korea: 11 years follow-up prospective study. Korean J Epidemiol 2005;27:182-90.

43. Korea Health Promotion Foundation. Effectiveness of health outcome in health plan 2020. Seoul: Korea Health Promotion Foundation, 2011.

44. Oh YM. Women's smoking and tobacco control policies in Korea. Tobacco-Free 2015;5:2-7. 